\title{
A nested randomised controlled trial of a leaflet, containing information on research, to increase the recruitment rate of reform (reducing falls with orthoses and a multifaceted podiatry) trial participants
}

\author{
Catherine Arundel*, David Torgerson, Laura Jefferson, Sarah Cockayne \\ From 2nd Clinical Trials Methodology Conference: Methodology Matters \\ Edinburgh, UK. 18-19 November 2013
}

\section{Background}

Poor recruitment is a major problem in randomised trials. Although pre-notification has been demonstrated to be an effective strategy for increasing response rates to postal questionnaires (Edwards et al, 2010), the usefulness of this approach to aid trial recruitment has never been evaluated.

This study, nested within the NIHR funded REFORM Trial, aimed to identify whether increasing understanding of research in potential trial participants, prior to being approached for consent, can increase trial recruitment.

\section{Methods}

Prospective participants for the REFORM trial were identified by local Podiatry or Falls clinics. A pilot trial showed a $3 \%$ recruitment rate. To have $80 \%$ power $(2 \mathrm{p}=0.05)$ and increase recruitment to $5 \%$, we needed to randomise 3300 participants (2:1 in favour of control arm) to receive a general leaflet about research ( 2 weeks prior to the REFORM consent packs being sent) or to receive no prior information. Leaflets are being mailed out in April to June 2013.

\section{Results}

Mail out for this nested sub study will be completed by 1st July 2013. The results of the study will be presented at the Clinical Trials Methodology Conference. The main outcome is the number of participants randomised between the two arms of the study.

University of York, York, UK

( 2013 Arundel et al; licensee BioMed Central Ltd. This is an Open Access article distributed under the terms of the Creative Commons Attribution License (http://creativecommons.org/licenses/by/2.0), which permits unrestricted use, distribution, and reproduction in any medium, provided the original work is properly cited.

\section{Discussion}

The trial findings should provide useful information about recruitment aids for researchers designing future randomised controlled trials.

\section{Published: 29 November 2013}

\section{Reference}

1. Edwards PJ, Roberts I, Clarke MJ, DiGuiseppi C, Wentz R, Kwan I, Cooper R, Felix LM, Pratap S: Methods to increase response rates to postal and electronic questionnaires. Cochrane Database of Systematic Reviews 2009,

doi:10.1186/1745-6215-14-S1-0109

Cite this article as: Arundel et al: A nested randomised controlled trial of a leaflet, containing information on research, to increase the recruitment rate of reform (reducing falls with orthoses and a

Submit your next manuscript to BioMed Central and take full advantage of:

- Convenient online submission

- Thorough peer review

- Immediate publication on acceptance

- Inclusion in PubMed, CAS, Scopus and Google Scholar

- Research which is freely available for redistribution 3, Art.No.: MR000008. DOI: 10.1002/14651858.MR000008.pub4. multifaceted podiatry) trial participants. Trials 2013 14(Suppl 1):0109.

- No space constraints or color figure charges \\ (Ciomed Central}

